\title{
Stability and Performance of Physically Immobilized Ionic Liquids for Mercury Adsorption from a Gas Stream
}

\section{Tauqeer Abbas ${ }^{\dagger}$, Lethesh Kallidanthiyil Chellappan ${ }^{\dagger}$, M. I Abdul Mutalib ${ }^{* *}$, Kuah Yong} Cheun $\dagger^{\dagger}$, Syed Nasir Shah ${ }^{\dagger}$, Salman Nazir $\S$, Amiruddin Hassan $\dagger^{\dagger}$, Mahpuzah bt Abai ${ }^{\dagger} \dagger$ and Eakalak Khan $f$

广 PETRONAS Ionic Liquid Centre, Universiti Teknologi PETRONAS, Bandar Seri Iskandar, 31750 Tronoh, Perak, Malaysia

† Process Technology R\&D, Technology and Engineering Division, PETRONAS Research Sdn. Bhd. Kajang, Malaysia

$\S$ Buskerud and Vestfold University College, Borre, Norway

$\$$ Department of Civil and Environmental Engineering, North Dakota State University, Fargo, USA

* Corresponding author:

E-mail: ibrahmat@petronas.com.my

Phone: $+\underline{605-3687562}$

Fax: $+\underline{605-3656176}$ 


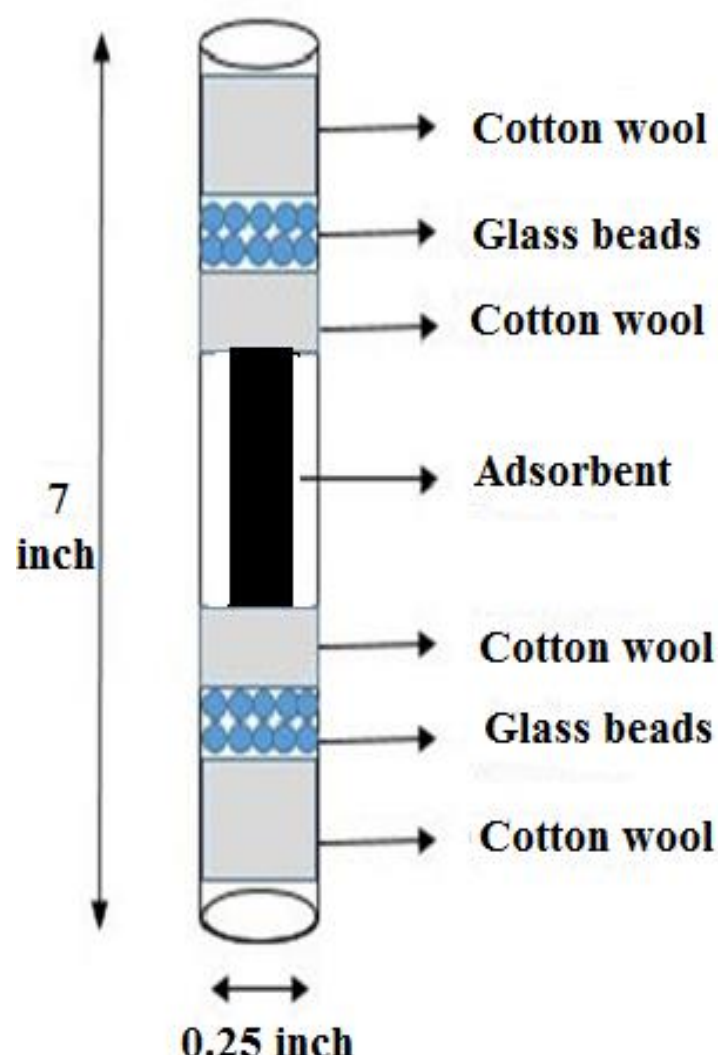

(a)

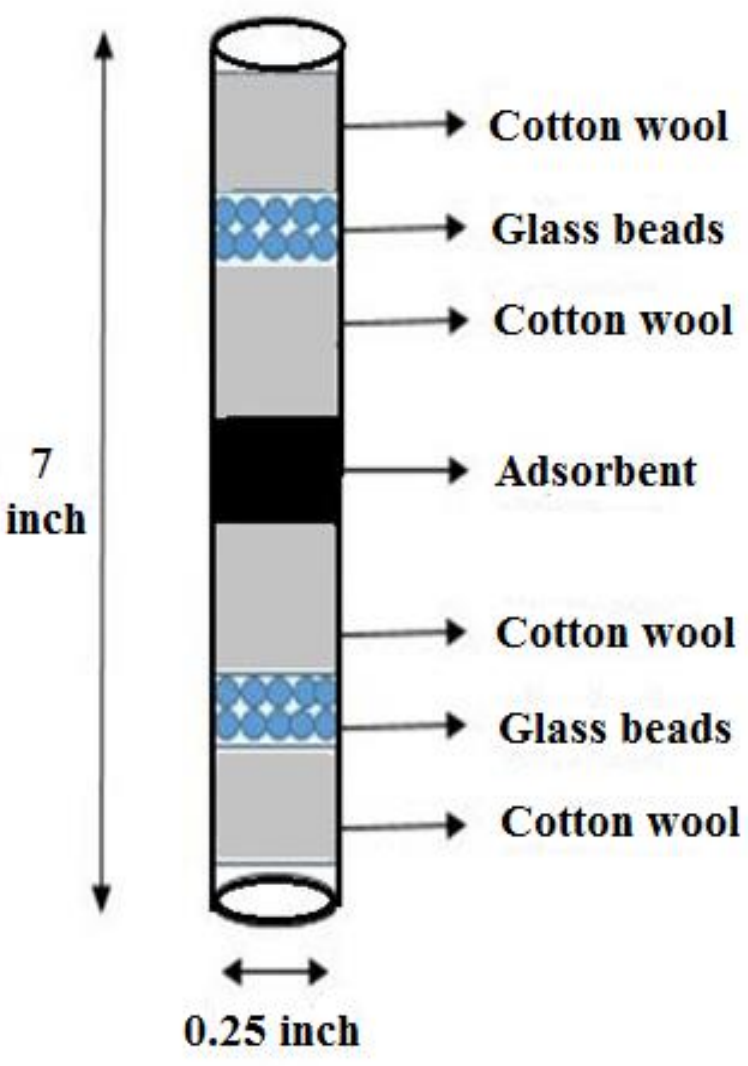

(b)

Figure S1. (a): Design of packed bed column for uncrushed/non powdered silica and carbon supported [Bmim] Cl and (b): Design of packed bed for breakthrough development (for powdered form of adsorbent). 
Supporting Information

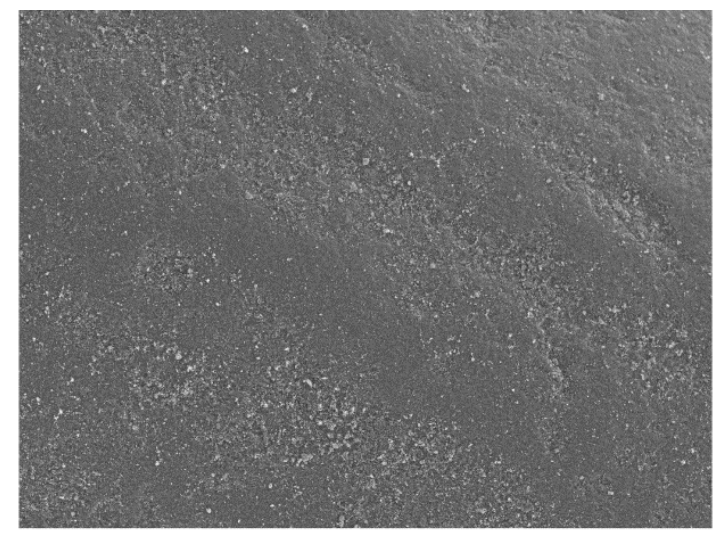

Electron Image 1

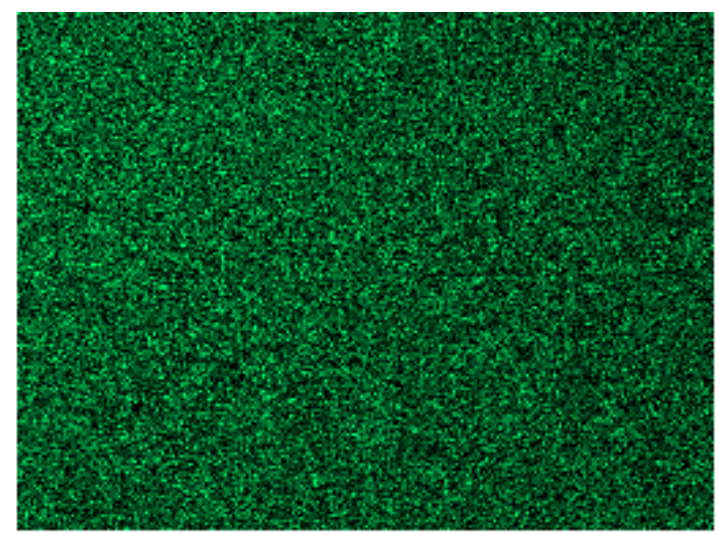

Si Ka1

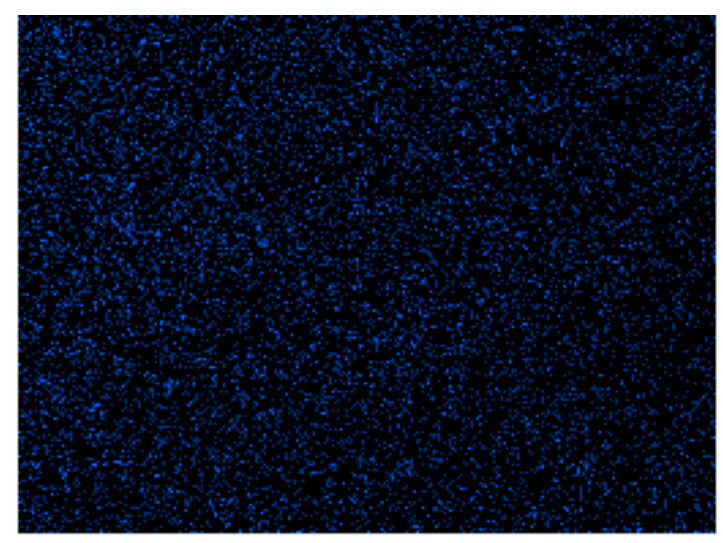

$\mathrm{ClKa1}$

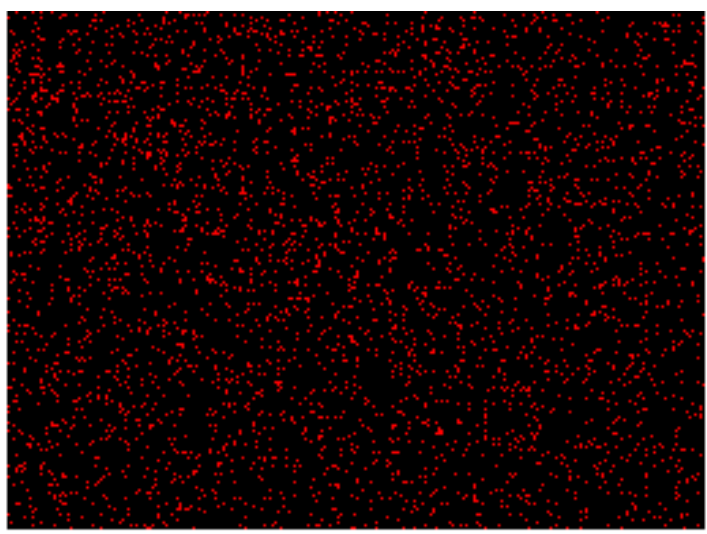

C Ka1_2

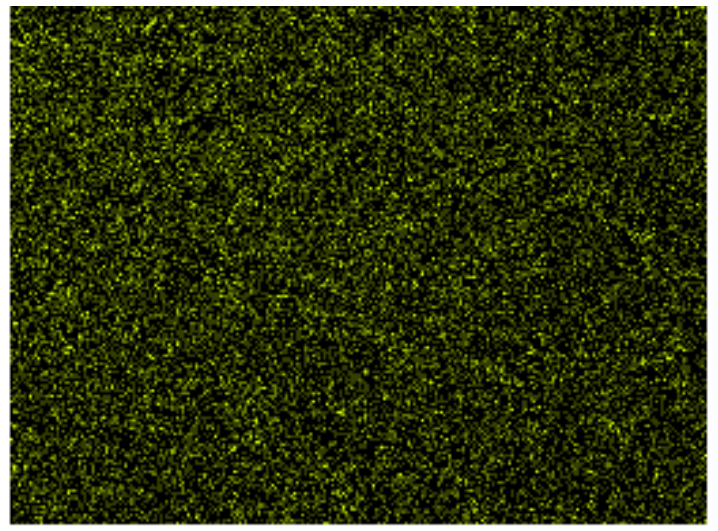

o Ka1

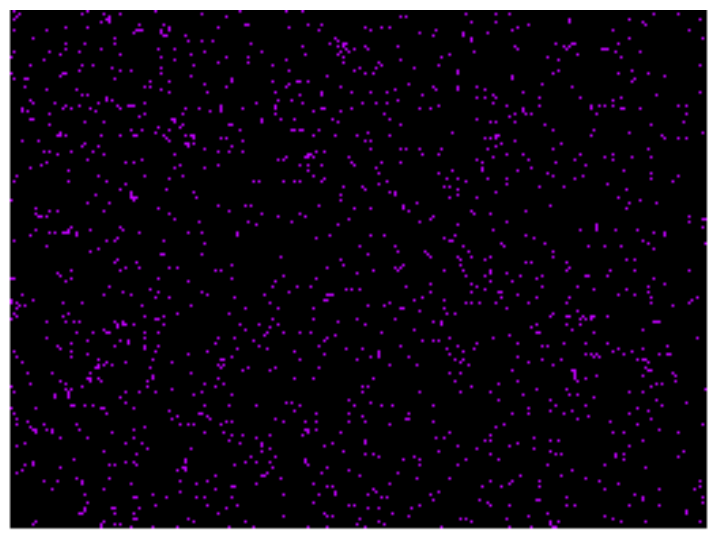

CaKa1

Figure S2: EDX mapping for fresh silica supported [Bmim]Cl. 
Supporting Information

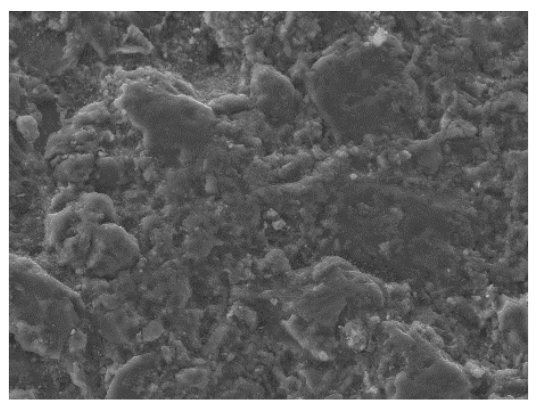

Electron Image 1

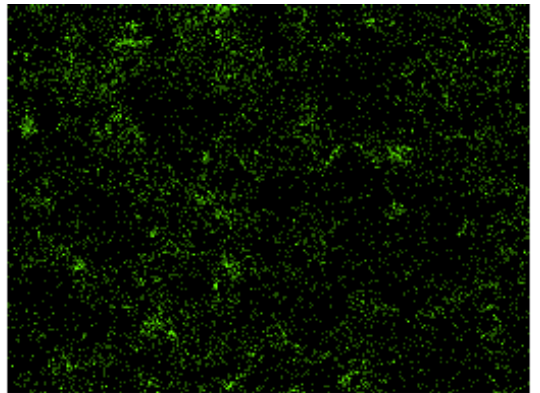

Al Ka1

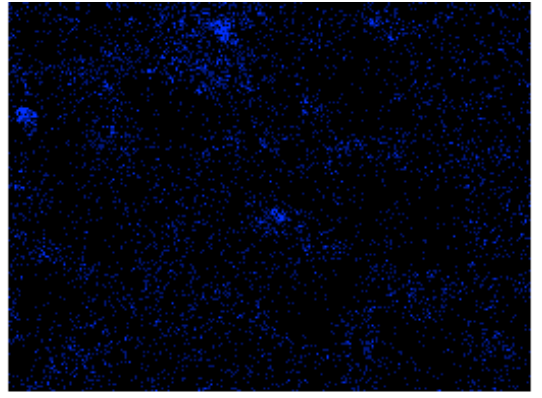

CaKa1

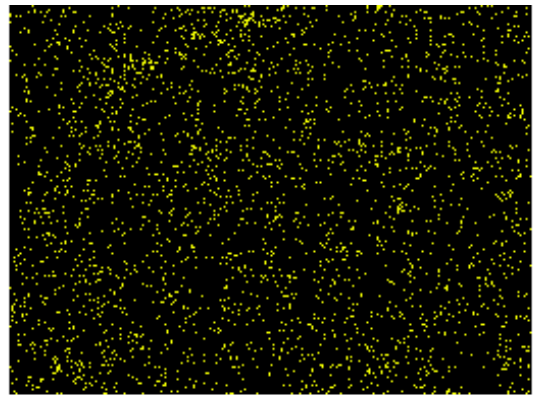

Mg Ka1_2

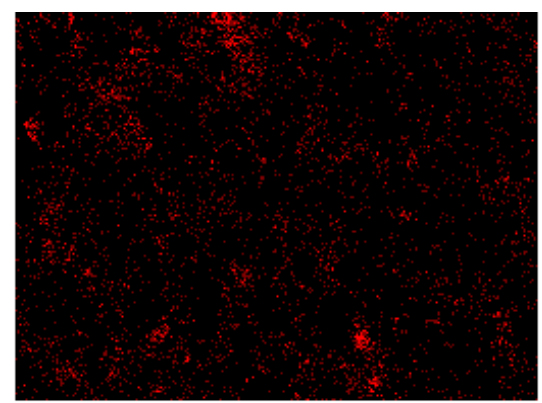

o Ka1

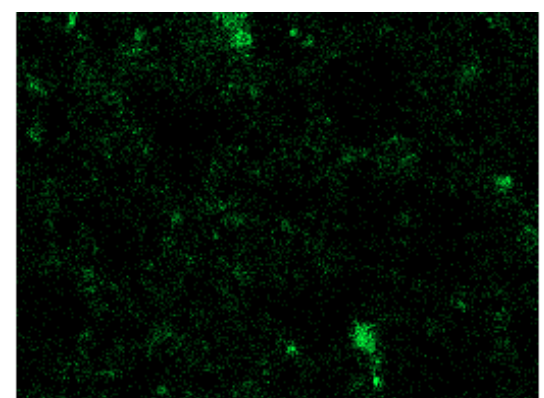

Si Ka1

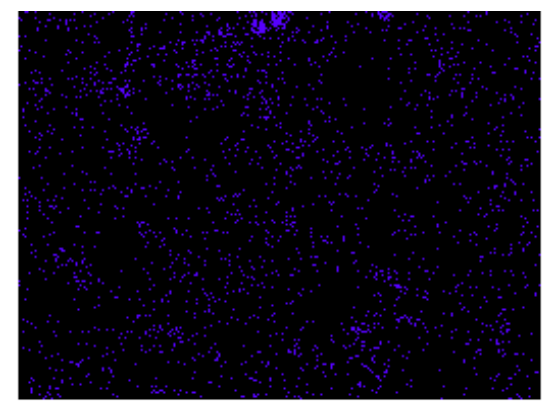

Fe Ka1

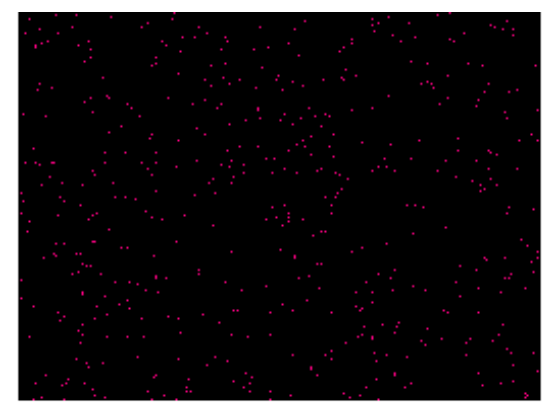

Hg La1

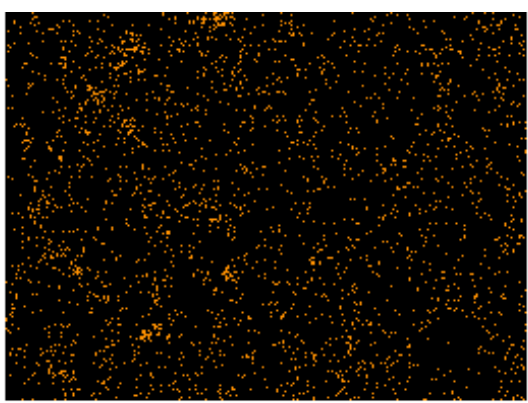

NaKa1_2

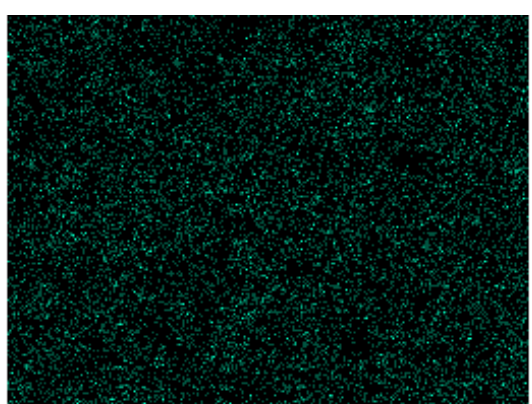

ClKa1

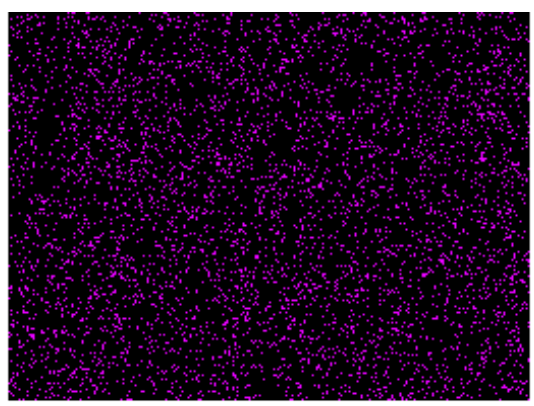

Mo La1

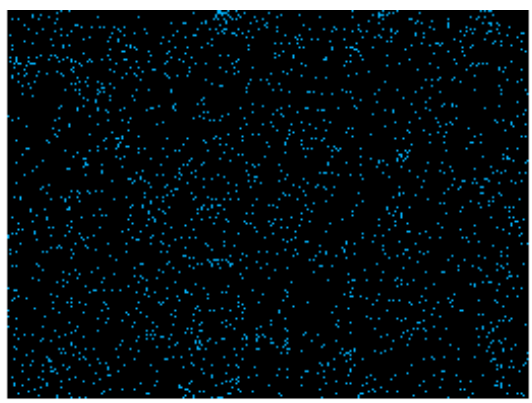

KKa1

Figure S3: EDX mapping for spent carbon supported [Bmim] Cl. 